$10-2003$

\title{
On the Mechanical Response in a Thermal Barrier System Due to Martensitic Phase Transformation in the Bond Coat
}

Anette M. Karlsson

Cleveland State University, a.karlsson@csuohio.edu

Follow this and additional works at: https://engagedscholarship.csuohio.edu/enme_facpub

Part of the Mechanical Engineering Commons

How does access to this work benefit you? Let us know!

Original Citation

Karlsson, A. M., 2003, "On the Mechanical Response in a Thermal Barrier System due to Martensitic Phase Transformation in the Bond Coat," Journal of Engineering Materials and Technology, 125(4) pp. 346-352.

This Article is brought to you for free and open access by the Mechanical Engineering Department at EngagedScholarship@CSU. It has been accepted for inclusion in Mechanical Engineering Faculty Publications by an authorized administrator of EngagedScholarship@CSU. For more information, please contact library.es@csuohio.edu. 


\author{
A. M. Karlsson \\ e-mail: karlsson@me.udel.edu \\ Department of Mechanical Engineering, \\ University of Delaware, \\ Newark, DE 19716
}

\section{On the Mechanical Response in a Thermal Barrier System Due to Martensitic Phase Transformation in the Bond Coat}

Recent studies have shown that Pt-aluminide-a common bond coat material in thermal barrier coatings-undergoes martensitic transformations during thermal cycling. The transformations are associated with both large transformation strain and a strain hysteresis, leading to accumulation of a mismatch strain. Thermal barrier systems based on Pt-aluminide bond coats are susceptible to interfacial morphological instabilities. In this study, we investigate how the cyclic martensitic transformation influences the morphology. Two key results are: (i) the morphological instabilities are highly sensitive to the thermomechanical properties of the substrate due to the martensitic transformation; (ii) the hysteresis associated with cyclic martensitic transformation cannot drive the morphological instabilities; the strains associated with the formation of the thermally grown oxide do.

\section{Introduction}

Thermal barrier systems are commonly used in the hot sections of modern gas turbines for aero-propulsion and power generation [1-5]. A typical design consists of a single-crystal nickel based superalloy coated with a bilayer that provides both thermal and oxidation protection. The bilayer consists of a bond coat, providing oxidation protection of the superalloy, and a ceramic top coat, providing thermal protection. The bond coat provides oxidation protection by it oxidizing, forming an oxide scale. The oxide scale is typically an alpha-aluminum oxide, $\alpha-\mathrm{Al}_{2} \mathrm{O}_{3}$, commonly referred to as the thermally grown oxide (TGO). A thermal gradient is maintained over the top coat due to active cooling of the superalloy substrate. Thus, the thermal barrier system is a four-layer system consisting of (Fig. 1) (i) the (thick) superalloy substrate, (ii) the bond coat (thickness: $30-100 \mu \mathrm{m}$ ), (iii) the thermally grown oxide, TGO (thickness: $2-10 \mu \mathrm{m}$ ), and (iv) the thermal barrier coating (TBC) (thickness: 120-200 $\mu \mathrm{m}$ ). The system evolves during its life, primarily manifested in the bond coat being consumed as it provides aluminum to the TGO.

Even though the TGO is relatively thin compared to the rest of the constituents, it is associated with many failure modes observed in thermal barrier systems [4-15]. A particular interesting property of the TGO is the "growth strain," which arise during oxidation. As the oxide scale grows at high temperature, it is subjected to both a lengthening and a thickening growth component (see for example [10]). The lengthening component is commonly referred to as growth strain, and may be interpreted as new alumina forming at the grain boundaries of the existing grains.

This study focuses on a widely used thermal barrier system based on Pt-aluminide bond coat, which initially has a single phase of $\beta$ (NiAl). This type of bond coat forms a relatively pure and slow growing $\alpha-\mathrm{Al}_{2} \mathrm{O}_{3}$, thus being more resistant to failure. A dominant failure mode in this system relates to the development of morphological instabilities (Fig. 1), a phenomenon that has recently received significant attention [4,9-16]. The current understanding of the failure mode-based on experimental, numerical and analytical studies - indicates that there are several essen- tial conditions that together cause the development of the morphological features [9-15]. These are (i) the intrinsic thermal mismatch between bond coat and TGO, causing large compressive stresses in the TGO at ambient temperatures; (ii) the initial imperfections in the bond coat/TBC interface, serving as nucleation sites for the instabilities [11]; (iii) the lengthening growth strain in the TGO, causing increasing compressive stresses during thermal exposure $[9,10,12-15]$; (iv) the crack-like imperfection in the toplayer, allowing the TGO to deform $[8,14]$; (v) the yielding in the bond coat, accommodating the TGO-deformation [10]; (vi) the high-temperature TGO creep, allowing the TGO to relax at higher temperatures [12]; and (vii) the thermal cycling, "resetting" the state of stress developed at high temperature $[10,12,15]$.

Most theoretical studies have assumed temperature independent properties in the bond coat. This study will incorporate temperature dependent material properties including martensitic phase transformation and bond coat yield strength. In particular, recent measurements [18-20] have revealed the temperature dependent properties of Pt-modified aluminide bond coats, including thermal expansion coefficients, transformation strains, and yield strength. The measurements [18-19] also show that the properties change as the system ages.

Two temperature dependent bond coat properties will be considered: (i) yield strain and (ii) misfit strains, where the latter consists of thermal strain and the transformation strain between Martensite $\left(\mathrm{L}_{0}\right)$ and Austenite $\left(\mathrm{B}_{2}\right)$.

Yield Strength. Three critical parameters govern the yield strength (Fig. 2): (i) the high temperature yield strength, $\sigma_{Y \text { min }}^{b c}$, (ii) the high temperature transition, $T_{2}$, and (iii) the rate at which the yield strength increase for decreasing temperatures, $-d \sigma_{Y}^{b c} / d T$. The influence of $\sigma_{Y \text { min }}^{b c}$, while ignoring martensitic transformation, was investigated in [10] and [15]. The lower bond coat yield strength is associated with more rapid formation of morphological instabilities. A small change in yield strength can significantly enhance the change in morphology. For simplicity, the parameters associated with the bond coat yield strength will be kept constant in this study.

Thermal and Transformation Strain. Martensitic transformations have been observed during thermal cycling by Chen et al. [19] and Zhang et al. [20]. The thermally induced bond coat strain 

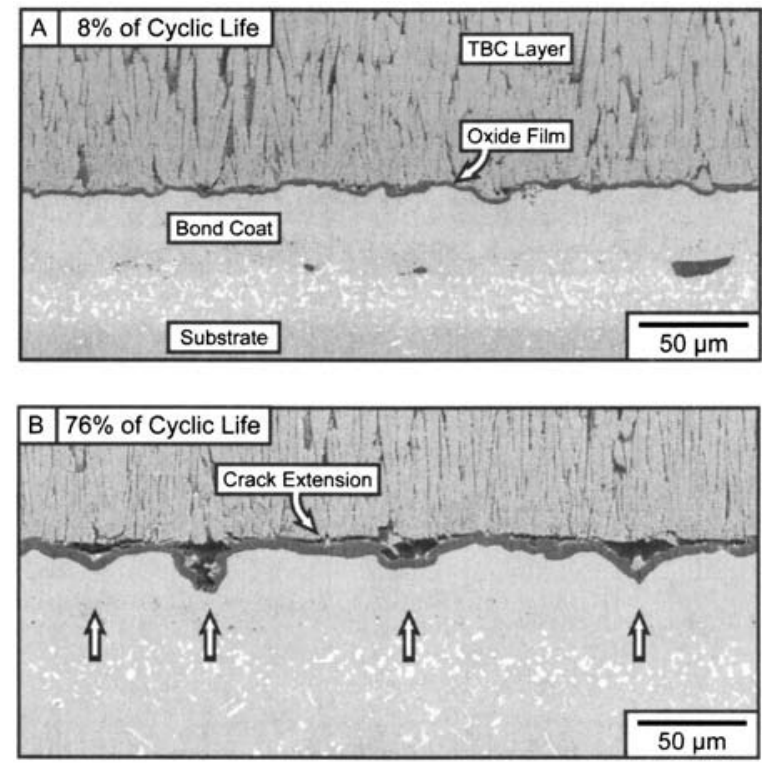

Fig. 1 An example of the development of morphological instabilities in a thermal barrier system, based on Pt-modified aluminde bond coat, subjected to thermal cycles (courtesy D.R. Mumm). The downward displacement of the TGO layer into the bond coat increases with thermal cycling (indicated as percentages of life) [11].

as a function of temperature, based on Chen et al. [19], is presented in Fig. 2(b). The thermally induced strain is defined by a range of parameters, including:

- The strain induced due to martensitic phase transformation, $\varepsilon_{m}$ (shrinking upon cooling)

- The onset temperature of martensitic transformation during cooling, $M_{\mathrm{s}}$, and heating, $A_{\mathrm{s}}$

- The temperature interval, $\Delta T_{m}$, for austenite to transform to martensite or reverse

- The coefficient of thermal expansion for the high temperature parent phase (Austenite), $\alpha_{B_{2}}$, and the low temperature martensitic phase, $\alpha_{L 1_{0}}$

Commonly, the onset temperatures during cooling and heating do not coincide. Thus, the loop $M_{s} \rightarrow M_{s}-\Delta T_{m} \rightarrow A_{s} \rightarrow A_{s}+\Delta T_{m}$ corresponds to the hysteresis during phase transformation. In this study, we will explore how this affects the development and morphology of the thermal barrier system.

In the following, we will investigate how temperature dependent properties affect the overall behavior of a thermal barrier system. In particular, three issues will be studied: (i) Can the hysteresis associated with the martensitic transformation drive the morphological changes observed in Fig. 1? (ii) Can the strain induced from the martensitic transformation be modeled by an "efficient" coefficient of thermal expansion? (iii) Can the constraint from the substrate in conjunction with martensitic transformation influence the morphological development?

\section{Model}

The hemispherical undulation representative of the actual imperfections (Fig. 1) is modeled with an axisymmetric layered model with an undulation, Fig. 3. The undulation growth is defined by two components: the downward displacement at the center of the undulation, $\delta_{\text {down }}$, and the upward displacement at the periphery of the undulation, $\delta_{u p}$, Fig. 3 .

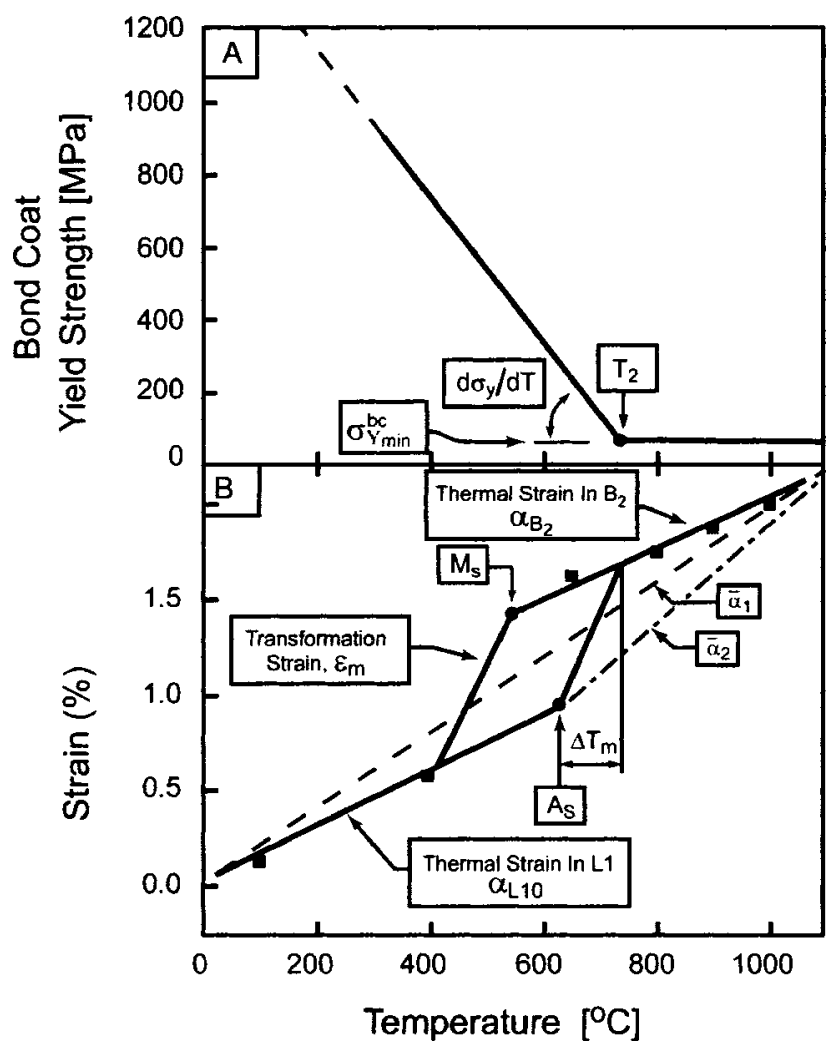

Fig. 2 (a) Yield strength and (b) thermal strain of the bond coat material [18-19]

The structure is initially assumed stress free at its highest temperature $T_{0}=1150^{\circ} \mathrm{C} .{ }^{1}$ The TGO is assumed to grow at this temperature (the growth temperature). Thus, at the growth temperature, the system is driven by the increment of growth strain. During cooling to room temperature, $T_{R T}$, and reheating to $T_{0}$, no growth strain is imposed. Consequently, during this sequence, the system is driven by the thermal expansion misfit between the bond coat and the TGO, $\Delta \alpha=\alpha_{b c}-\alpha_{t g o}(\Delta \alpha>0)$ and by the martensitic phase transformation strain, $\varepsilon_{m}$.

The bond coat is assumed linear-elastic and perfectly-plastic with temperature-dependent yield strength according to Fig. 2(a), and a temperature-dependent thermal strain according to Fig. 2(b). To simplify the simulation, the high temperature TGO-creep is modeled by perfectly plastic behavior, thus making the numerical model time-independent. This is justified by the investigation focusing on accumulation of non-elastic strain after several cycles. ${ }^{2}$ The yield strength is assumed to be the plateau stress for long term relaxation (creep). This stress is commonly referred to as "growth stress" for thermally grown oxides. Thus, in the model, the TGO only undergoes elastic deformations, except at the growth temperature where the TGO is linear-elastic and perfectlyplastic with yield strength $\sigma_{Y}^{\text {tgo }} .^{3}$

The nonelastic TGO-strain plays a central role in the system development, differentiating between cyclic and isothermal response [12]. The following scenario is observed at the elevated temperature, $T_{0}$ : When oxidation occurs at $T_{0}$, the compressive

${ }^{1}$ The various layers are deposited close to this temperature, thus the structure is assumed to be stress free.

${ }^{2}$ In classic continuum mechanics, used here, creep and plastic yield are only differentiated by the former being a time dependent property. The physical cause of creep (i.e., diffusion, grain boundary sliding) and plasticity (i.e., dislocation motion) is not incorporated in these model.

${ }^{3}$ This is achieved in the numerical model by letting $\sigma_{Y}^{\text {tgo }}=10 \mathrm{GPa}$ for $T$ $<1050^{\circ} \mathrm{C}, \sigma_{Y}^{\text {tgo }}=300 \mathrm{MPa}$ for $T>1050^{\circ} \mathrm{C}$, and letting $\sigma_{Y}^{\text {tgo }}$ vary linearly in between. 


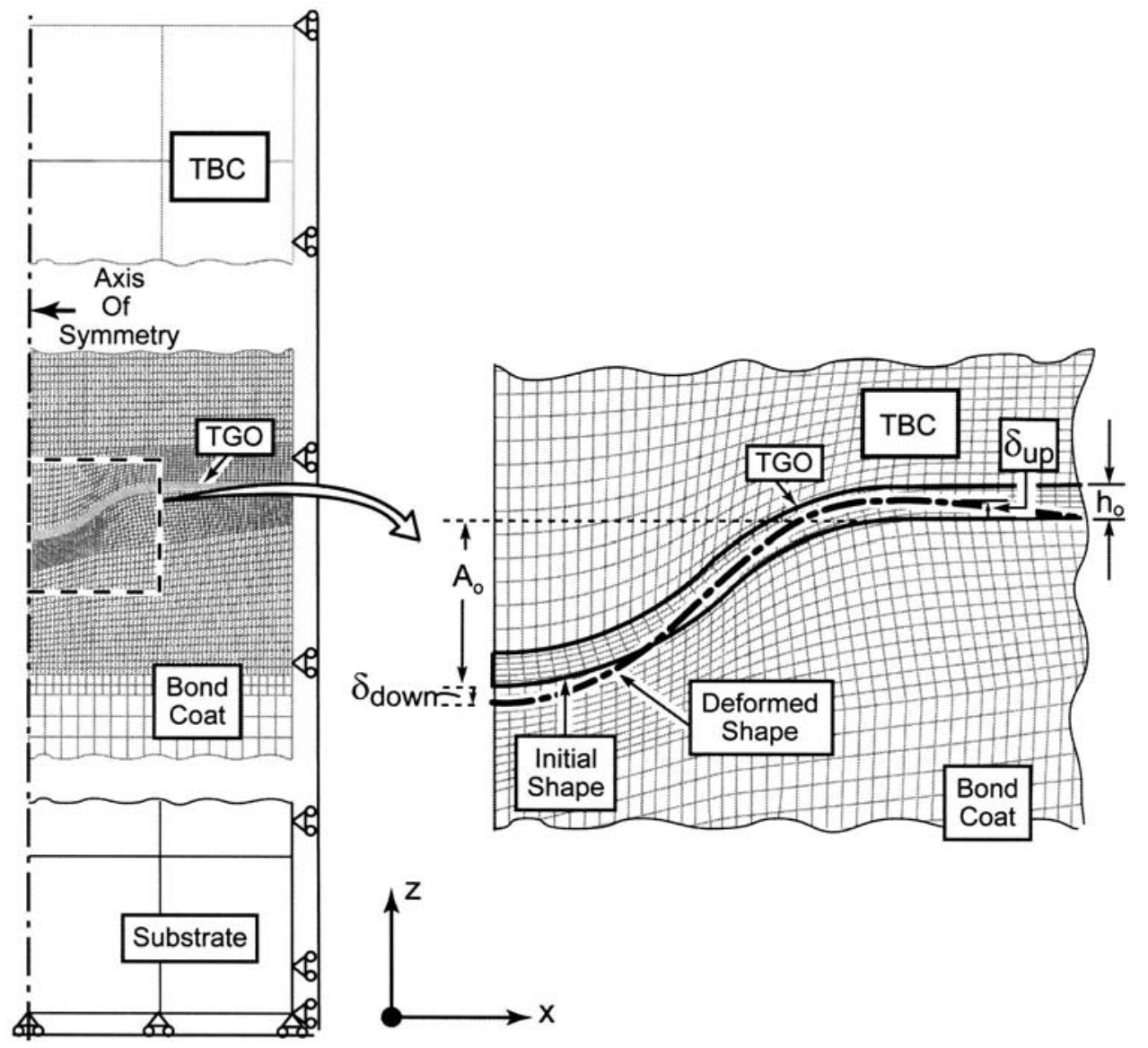

Fig. 3 An example of the finite element model, consisting of the substrate $(2 \mathrm{~mm})$, bond coat $(50 \mu \mathrm{m})$, TGO (initially $0.5 \mu \mathrm{m})$, and top coat $(100 \mu \mathrm{m})$

TGO stresses increases. Subsequently, the yield stress is reached, and the TGO yields. The remaining of the lateral growth strain is redistributed as thickening growth strain.

The finite element code ABAQUS [17] has been used to perform the simulations, utilizing large deformation theory. Growth of the TGO is simulated by imposing stress-free strains in accordance with a user subroutine, uexpan [10]. Based on the experimental observation, the in-plane strain is imposed uniformly through the TGO-thickness, while the thickening component is only applied at the elements closest to the bond coat. In a similar manner, the martensitic phase transformation is imposed as a stress-free strain, assuming that the transformation is thermally induced, independent of the current state of stress. The heat loss/ generation associated with martensitic transformation is ignored.

\section{Simulations}

The simulations will explore:

- the notion that the martensitic transformations can drive the morphological instabilities seen in Fig. 1

- the possibility of using an "effective coefficient of thermal expansion" instead of modeling the actual phase transformation

- the constraint the substrate and the top coat impose during the phase transformation

The structural response is highly nonlinear and will first be illustrated by investigating the single cycle response. With this established, the development of multiple cycles will be discussed. Table 1 shows the materials properties used in the simulations. To simulate the martensitic transformation, the following values are used: $M_{s}=600^{\circ} \mathrm{C} ; A_{s}=700^{\circ} \mathrm{C}, \Delta T_{m}=100^{\circ} \mathrm{C}$ [18]. The slope of the yield strength is assumed to be $d \sigma_{Y}^{b c} / d T=-1.2 \mathrm{MPa} /{ }^{\circ} \mathrm{C}$ [19]. The TGO growth components are $\Delta \varepsilon_{g}=10^{-3}$ and $\Delta \varepsilon_{\text {Thick }}$ $=10^{-2}$ respectively.

3.1 Single-Cycle Response. To elucidate the system response, we will first consider the initial single-cycle response where we for simplicity ignore the top coat. A typical bond coat element close to the TGO interface is investigated in Fig. 4.

The system starts stress free at elevated temperatures $\left(1150^{\circ} \mathrm{C}\right)$. After a small temperature drop $\left(\Delta \mathrm{T} \approx 100^{\circ} \mathrm{C}\right)$ the bond coat yields (Fig. 4(c)) and starts to accumulate plastic strain (Fig. 4(a)). The bond coat continues to yield until the temperature falls below $T$ $<T_{2}=800^{\circ} \mathrm{C}$. Below this temperature, the yield strength increases and the bond coat becomes elastic. When the phase transformation starts, $T=M_{s}=600^{\circ} \mathrm{C}$, the bond coat stress increases rapidly (Fig. 4(c)), eventually resulting in bond coat yielding and additional accumulation of plastic strain (Fig. 4(a)). After the

Table 1 Materials properties used in the model

\begin{tabular}{|c|c|c|c|}
\hline & Material & $\begin{array}{c}\text { Young's Modulus } \\
{[\mathrm{GPa}]}\end{array}$ & $\begin{array}{c}\text { Coefficient of } \\
\text { Thermal Expansion } \\
{\left[\mathrm{ppm}^{\circ} \mathrm{C}\right]}\end{array}$ \\
\hline TBC & $\begin{array}{c}\text { Porous yttria } \\
\text { stabilized zircona }\end{array}$ & 20 & 11 \\
\hline TGO & $\alpha$-alumina & 380 & 8.6 \\
\hline Bond Coat & $\begin{array}{l}\text { Pt-modified } \\
\text { aluminide }\end{array}$ & 110 & $\begin{array}{l}12.5 \text { for } T<M_{s} \\
14.5 \text { for } T>A_{s}\end{array}$ \\
\hline Substrate & René 5 & 110 & $10.5-14.5$ \\
\hline
\end{tabular}



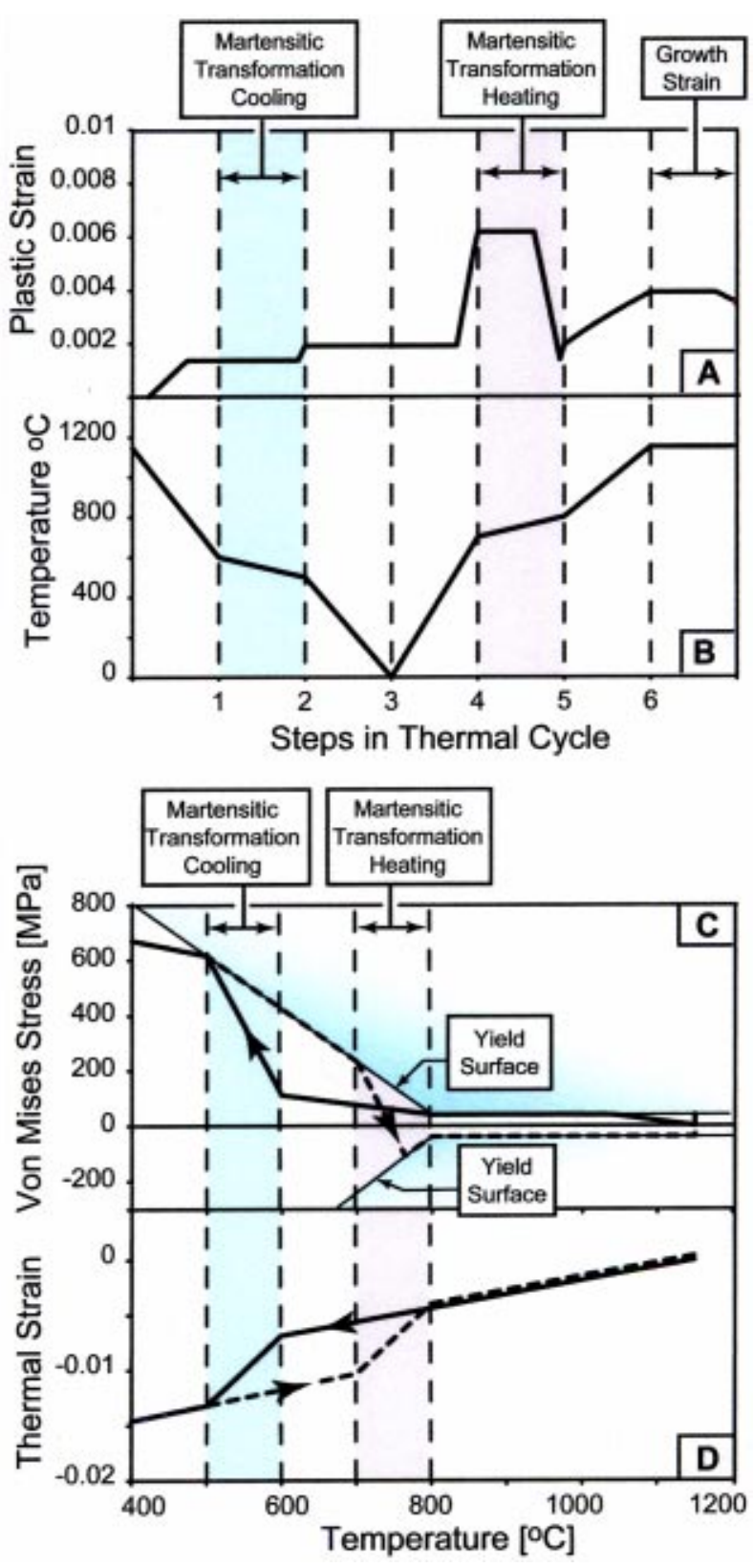

Fig. 4 The response of the system during the first cycle in a typical bond coat particle: (a) The incremental strain and (b) temperature as a function of the steps in the thermal history. (c) Mises stress and (d) thermal strain as a function of the temperature.

phase transformation is completed at $T=M_{s}-\Delta T_{m}=M_{f}$ $=500^{\circ} \mathrm{C}$, the structure once again becomes elastic, and remains elastic during cooling to room temperature.

Upon reheating the bond coat remains elastic until the temperature reaches $T=M_{f}=500^{\circ} \mathrm{C}$. As the temperature is further increased, the bond coat will yield (Fig. 4(c)), exhibiting forward yielding. This results in additional accumulation of plastic strain (Fig. 4(a)). The bond coat will yield until the reverse martensitic transformation starts at $T=A_{s}=700^{\circ} \mathrm{C}$, resulting in an elastic response followed by reverse yielding. The bond coat element will continue to yield until the maximum temperature is reached, $1150^{\circ} \mathrm{C}$. At this temperature, the bond coat oxidizes to form additional TGO, simulated by applying growth strain. Initially, the bond coat responds elastically, but will eventually yield. Even though the bond coat yields, the TGO-stresses continues to in-

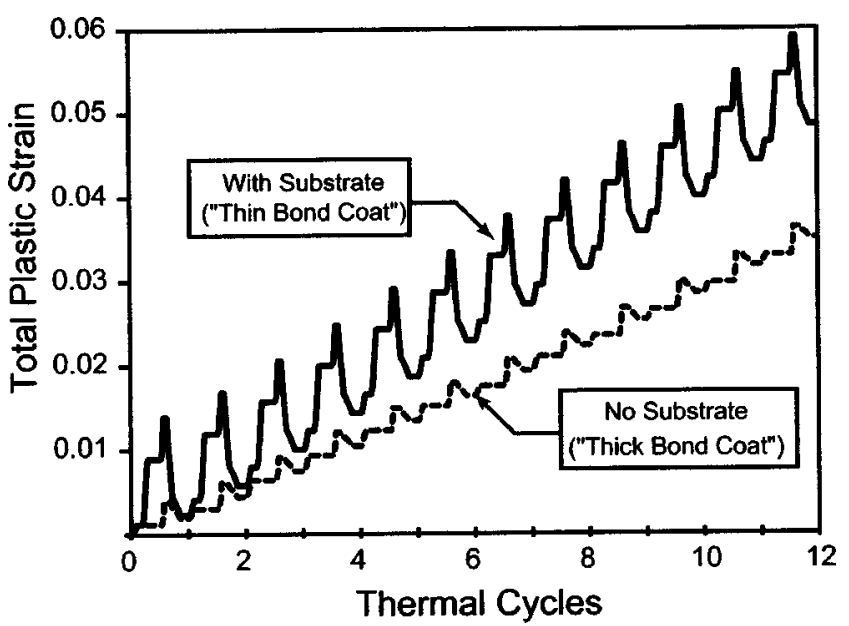

Fig. 5 The plastic strain accumulation during 12 cycles comparing "thick" to "thin" bond coat. For thick bond coat, the substrate has identical material properties as the bond coat, including martensitic transformation. For thin bond coat, the substrate does not undergo martensitic transformations.

crease with accumulation of growth strain. Eventually the TGO may yield (not shown), bringing the bond coat back to its elastic regime. When the bond coat yields during oxidation, more growth strain is allowed to accumulate, thus increasing the driving force for amplitude growth.

The above discussion corresponds to a typical development of the bond coat close to the TGO interface. The magnitudes and some of the nuances will vary depending on location of the bondcoat-element in question, but the general behavior is true for locations close to the $\mathrm{TGO} /$ bond coat interface.

In particular, we note that the forward yielding upon reheating is a novel behavior, directly associated with martensitic transformations.

3.2 Cyclic Response. We will next consider the response of the system during thermal cycling. The cyclic development is of importance, since the morphological instabilities do not develop during isothermal conditions. Ultimate failure occurs after 100's of cycles [11]. The failure is a complicated combination of stress and strain development in combination with crack growth and coalescence. In the following, we will limit the analysis to 12 cycles, to illuminate the cyclic response of the system due to martensitic transformation. The development and propagation of cracks are beyond the scope of this work.

Four issues will be discussed: (i) the effect of the constraint the substrate introduces, (ii) the effect of the growth strain, (iii) the effective coefficient of thermal expansion, and (iv) the stress development in the top coat. In the first three cases the top coat is ignored in the model.

3.2.1 Effect of Substrate. In order to elucidate the response of mismatch between substrate and bond coat (Fig. 5), two cases are discussed: (i) "thick bond coat" where the substrate is given identical properties as to the bond coat (including phase transformation); and (ii) "thin bond coat" where only the bond coat undergoes martensitic transformation. In both cases the substrate is assumed elastic. In the former case no mismatch is induced during martensitic transformation. The latter corresponds to the real geometry. The two cases have different plastic zones, Figs. 6(a) and 6(b). For "thin bond coat," the strain mismatch during martensitic transformation causes overall bond coat yielding. This results in large plastic strain accumulation (Fig. 5). Due to the overall bond coat yielding, the TGO can easily relax its compressive stress, caused by thermal mismatch and the TGO growth, by pushing into the bond coat. 


\section{\begin{tabular}{|l|l|}
\hline A & With Substate \\
\hline
\end{tabular}}
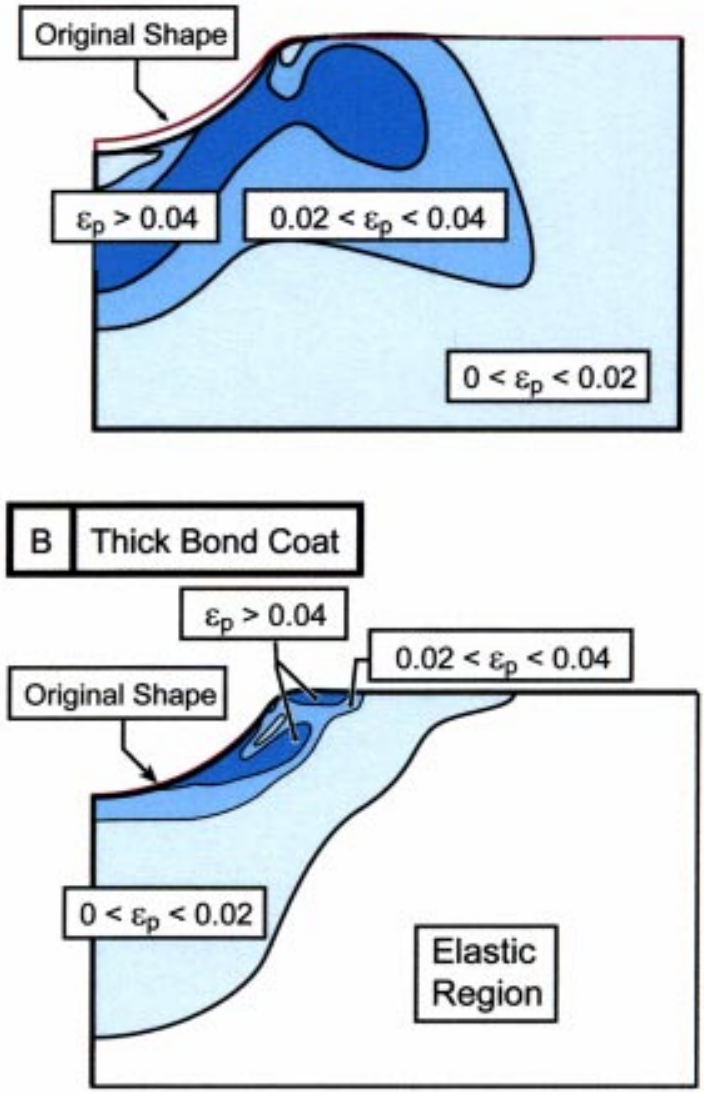

\section{\begin{tabular}{|l|l|}
\hline C & Effective CTE, $\bar{\alpha}_{2}$ \\
\hline
\end{tabular}}

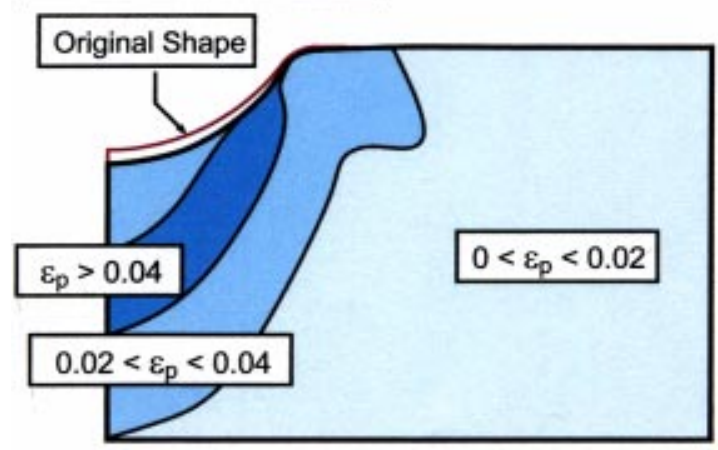

Fig. 6 Contour plot of the plastic strain accumulation in bond coat during 12 cycles: (a) With Substrate ("thin bond coat"), (b) Thick bond coat (substrate has identical properties as to the bond coat), (c) Using the effective coefficient of thermal expansion $\bar{\alpha}_{2}$, see Fig. 3.

The rate of imperfection growth - translated as the amplitude change $\delta_{\text {tot }}=\delta_{\text {up }}+\delta_{\text {down }}$ (Fig. 3) - depends on the relative thermal expansion coefficient between the substrate and bond coat, Fig. 7. The highest rate of imperfection growth (Fig. 7) is achieved when the substrate has higher thermal expansion coefficient than the bond coat, $\alpha_{s}>\alpha_{b c}$. Thus, according to the numerical results, reducing the thermal mismatch between the bond coat and the substrate can slow the imperfection growth. The process behind this development is an intricate nonlinear process and is currently being investigated [21].

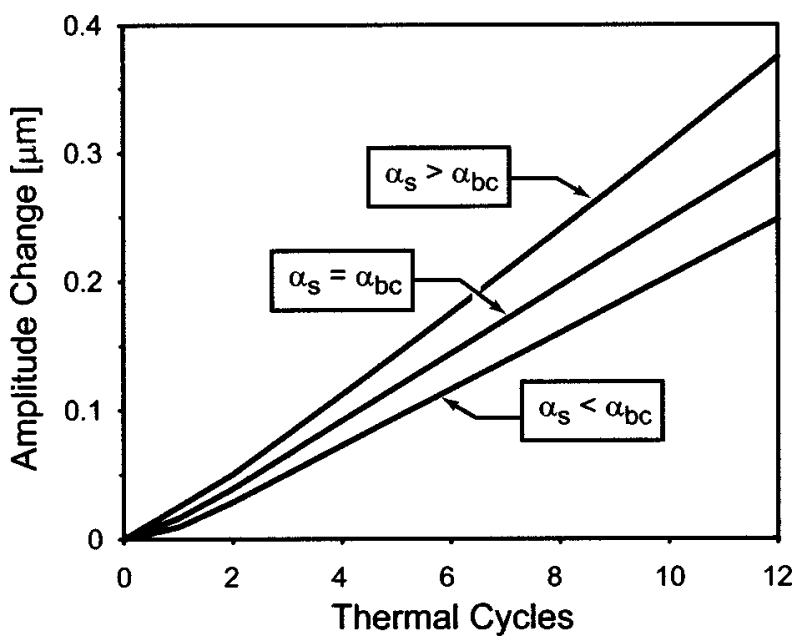

Fig. 7 The development of the amplitude change over 12 cycles, comparing various thermal coefficients of expansion for the substrate

Thus, in order to correctly predict the development of the structure, the thermo-mechanical properties of the substrate are as important as the properties of the bond coat and the TGO.

3.2.2 Growth Strain. The cyclic response reveals the importance of growth strain (oxidation) of the TGO, Fig. 8. When growth strain is not incorporated, the system undergoes shakedown resulting in vanishing accumulation of plastic strain (Fig. 8(a)) and vanishing amplitude changes (Fig. 8(b)). Thus, the hysteresis from the Martensitic transformation cannot alone drive the amplitude change.

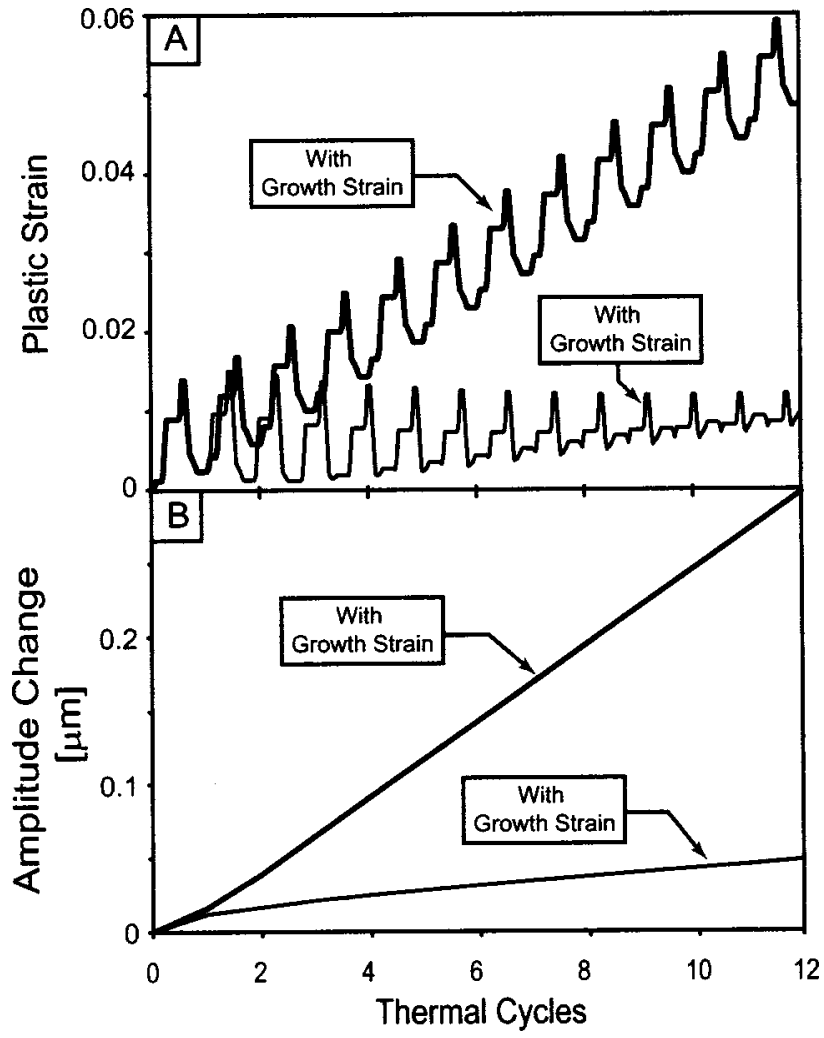

Fig. 8 The development over 12 cycles using and ignoring growth strain: (a) plastic strain and (b) amplitude change. 


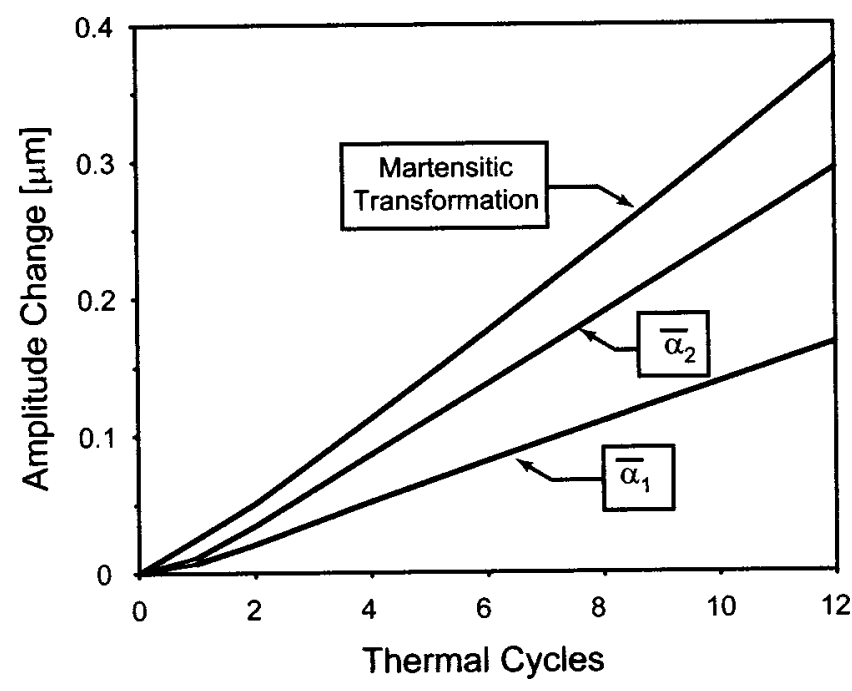

Fig. 9 The development of the amplitude change over 12 cycles using efficient coefficient of thermal expansion

3.2.3 Effective Coefficient of Thermal Expansion. The transformation strain caused by the martensitic transformation adds significant complexity to the numerical scheme. It is therefore pertinent to investigate if the calculations can be simplified by determining and using an "Effective Coefficient of Thermal Expansion," ECTE, $\bar{\alpha}$. Two possible methods for selections are indicated in Fig. 2(b). $\bar{\alpha}_{1}$ corresponds to the average expansion over the total temperature interval, and $\bar{\alpha}_{2}$ corresponds to a maximum expansion given by the geometry of the thermal straintemperature space. The former case corresponds to the apparent thermal strain, observed within the temperature interval. The latter is inspired by two factors; (i) yielding occurs at high temperatures, where the bond coat has its lowest yield strain; and (ii) no yielding occur for temperature below $T_{2}$, except during martensitic transformation. Thus, by using $\bar{\alpha}_{2}$ we expect an upper bound for plastic strain accumulation during thermal cycling.

Unfortunately, the amplitude change is not predicted by any of the two cases considered (Fig. 9). Moreover, the accumulation of plastic strain is completely different between modeling martensitic transformation and using ETCE, Figs. 6(a) and 6(c). Thus, the investigated ECTE are not appropriate ways to simulate the martensitic transformation. Eventhough the same amount of mismatch strain is imposed on the system, it is applied in different manners. Since the system is highly nonlinear and nonconservative (due to plasticity) the system is path dependent. It follows that it is pertinent to impose the mismatch strain in the correct sequence. Thus, the suggested ways of defining ETCE do not correctly predict the behavior of the system. ${ }^{4}$

3.3.4 The Effect of the Top Layer. So far, the results discussed have been based on simulations excluding the top coat, the thermal barrier itself. Some key results when including the top coat will be discussed in this section. The inclusion of the top coat introduces a range of parameters, including: the elastic modulus of the top coat and the degree of anisotropy; and the presence and location of traction free planes (cracks) [14]. However, these parameters will not be systematically investigated, since the focus will be on the martensitic transformation in the bond coat. Thus, the simulation will assumed a perfectly intact top coat (no traction free planes) and the elastic modulus will be set to $E=20 \mathrm{GPa}$ in plane and $E=200 \mathrm{GPa}$ out of plane.

Determining the stresses in the top coat is critical, since the

${ }^{4}$ It may be possible that other schemes for approximating the mismatch strain can be developed - which must correctly predict both amplitude change and plastic strain accumulation — but this will not be pursued presently.

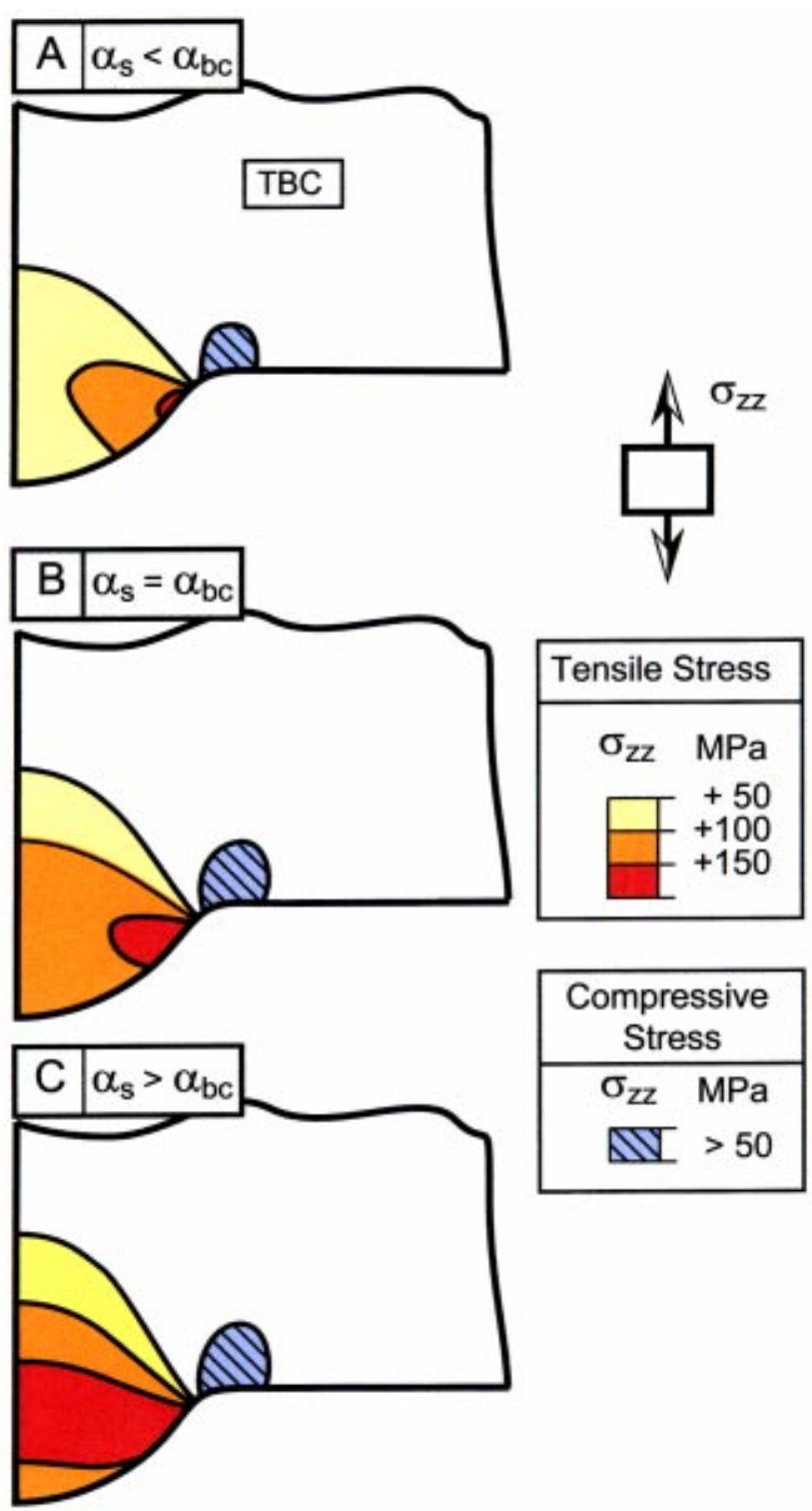

Fig. 10 Development of stresses in the TBC, using various CTE in the substrate; (a) $\alpha_{s}>\alpha_{b c}$; (b) $\alpha_{s}=\alpha_{b c}$; (c) $\alpha_{s}<\alpha_{b c}$. The difference refers to elevated temperature.

stresses will govern the initiation, growth and coalescence of cracks. These are the cracks that ultimately grow to critical length, causing the top coat to buckle and spall, leaving the metal exposed to the hot temperatures [1-7]. Karlsson et al. [14] showed that the stresses in the top coat grow for each cycle, where the magnitude quickly can reach critical values, promoting crack initiation and growth. Similar cyclic increase in stress is observed when the Martensitic transformations are considered, Fig. 10. The stress in the top coat changes when the thermal expansion coefficient of the substrate is changed. For example, the stresses in TBC are lower when the substrate has higher coefficient of thermal expansion to that of the bond coat, $\alpha_{s}>\alpha_{b c}$. This is consistent with the observation absent top coat. Thus, the thermo-mechanical properties of the substrate directly will influence the state of stress in the top coat. The details of the mechanics behind this are currently being investigated [21].

\section{Concluding Remarks}

The effect the martensitic phase transformation in the bond coat has on the development of morphological instabilities in a class of 
thermal barrier systems has been investigated by utilizing a numerical scheme. To simulate the thermal load conditions, the model is subjected to a loading sequence including cooling, heating, forward and reveres martensitic phase transformation, and growth strain. The phase transformation and the growth strain are modeled by imposing appropriate stress free strains in the FEmodel. The phase transformation and growth strain are assumed thermally induced, independent of the state of stress.

Several important observations are made from the model:

1. The phase transformation cannot by itself drive the system to increase the undulation size, but the lateral strain associated with the oxide growth ("growth strain") must be present.

2. The thermo-mechanical properties of the substrate, in particular the coefficient of thermal expansion, rule the behavior of the system. This follows from the substrate being significantly thicker than the other constituents. Thus, in order to predict the failure mechanism of the thermal barrier system, it is crucial to incorporate representative properties of the substrate.

3. The cooling-heating process including the martensitic transformation cannot be simulated with an effective coefficient of thermal expansion.

The plastic deformation in the bond coat occurs at the two segments in the thermal history: (i) at the highest temperatures, where the bond coat strength is extremely low, and (ii) within the temperature range of martensitic transformation. Thus, it is potentially possible to optimize a system, reducing the stresses in the top layer, by designing the range where the martensitic transformation occurs. However, the martensitic transformation will only occur during a particular time interval in the lifetime of the TBC. Thus, it may be desirable to design the bond coat so that martensitic transformations do not occur at all, reducing the cyclic strain in the system.

In summary, the martensitic transformation in the bond coat give rise to a complex non-linear mechanical behavior of a thermal barrier coating; sometimes with unexpected results. In spite of the complex response, this study indicates that there are opportunities to optimize the bond coat properties so to minimize top coat stresses, and in this way extending the life of the thermal barrier coating.

\section{References}

[1] Miller, R. A., 1984, “Oxidation-Based Model for Thermal Barrier Coating Life,” J. Am. Ceram. Soc., 67, pp. 517-521.
[2] Strangman, T. E., 1985, "Thermal Barrier Coatings for Turbine Airfoils," Thin Solid Films, 127, pp. 93-105.

[3] DeMasi-Marcin, J. T., and Gupta, D. K., 1994, "Protective Coatings in the Gas-Turbine Engine,” Surf. Coat. Technol., 68/69, pp. 1-9.

[4] Wright, P. K., and Evans, A. G., 1999, "Mechanisms Governing the Performance of Thermal Barrier Coatings," Curr. Opin. Solid State Mater. Sci., 4, pp. 255-265.

[5] Johnson, C. A., Ruud, J. A., Bruce, R., and Wortman, D., 1998, "Relationships Between Residual Stress, Microstructure and Mechanical Properties of Electron Beam Physical Vapor Deposition Thermal Barrier Coatings," Surf. Coat. Technol., 109, pp. 80-85.

[6] Gell, M., Vaidyanathan, K., Barber, B., Cheng, J., and Jordan, E., 1999, "Mechanism of Spallation in Platinum Aluminide/Electron Beam Physical Vapor-Deposited Thermal Barrier Coatings," Metall. Trans. A, 30, pp. 427435.

[7] Padture, N. P., Gell, M., and Jordan, E. H., 2002, “Thermal Barrier Coatings for Gas-Turbine Engine Applications," Science, 12, pp. 280-284.

[8] Ruud, J. A., Bartz, A., Borom, M. P., and Johnson, C. A., 2001, "Strength Degradation and Failure Mechanisms of Electron-Beam Physical-VaporDeposited Thermal Barrier Coatings," J. Am. Ceram. Soc., 84, pp. 1545-1552.

[9] He, M. Y., Evans, A. G., and Hutchinson, J. W., 2000, "The Ratcheting of Compressed Thermally Grown Thin Films on Ductile Substrates," Acta Mater., 48, pp. 2593-2601.

[10] Karlsson, A. M., and Evans, A. G., 2001, "A Numerical Model for the Cyclic Instability of Thermally Grown Oxides in Thermal Barrier Systems," Acta Mater., 49, pp. 1793-1804.

[11] Mumm, D. R., Evans, A. G., and Spitsberg, I., 2001, "Characterization of Cyclic Displacement Instability for a Thermally Grown Oxide in a Thermal Barrier System," Acta Mater., 49, pp. 2329-2340.

[12] Karlsson, A. M., Hutchinson, J. W., and Evans, A. G., 2002, "A Fundamental Model of Cyclic Instabilities in Thermal Barrier Systems," J. Mech. Phys. Solids, 50, pp. 1565-1589.

[13] Karlsson, A. M., Levi, C. G., and Evans, A. G., 2002, "A Model Study of Displacement Instabilities During Cyclic Oxidation," Acta Mater., 50, pp. $1263-1273$.

[14] Karlsson, A. M., Xu, T., and Evans, A. G., 2002, "The Effect of the Thermal Barrier Coating on the Displacement Instability in Thermal Barrier Systems," Acta Mater., 50, pp. 1211-1218.

[15] Karlsson, A. M., Hutchinson, J. W., and Evans, A. G., 2003, "The Displacement of the Thermally Grown Oxide in Thermal Barrier Systems Upon Temperature Cycling," Mater. Sci. Eng., A351, pp. 244-257.

[16] Pennefather, R. C., and Boone, D. H., 1995, "Mechanical Degradation of Coating Systems in High-Temperature Cyclic Oxidation," Surf. Coat. Technol., 76-77, pp. 47-52.

[17] ABAQUS, Hibbitt, Karlsson and Sorensen Inc, Pawtucket, RI.

[18] Pan, D., Chen, M. W., Wright, P. K., and Hemker, K. J., 2003, "Evolution of a Diffusion Aluminide Bond Coat for Thermal Barrier Coatings During Thermal Cycling," Acta Mater., 51, pp. 2205-2217.

[19] Chen, M. W., Ott, R. T., Hufnage, T. C., Wright, P. K., and Hemker, K. J., 2003, "Microstructural Evolution of Platinum Modified Nickel Aluminide Bond Coat During Thermal Cycling," Surf. Coat. Technol., 163-164, pp. 2530 .

[20] Zhang, Y., Haynes, J. A., Pint, B. A., Wright, I. G., and Lee, W. Y., 2003, "Martensitic Transformation in NiAl and (Ni,Pt)Al Bond Coatings," Surf. Coat. Technol., 163-164, pp. 19-24.

[21] Karlsson, A. M., and Evans, A. G., 2003, work in progress. 